\title{
Role of Gatekeepers in Suicide Prevention During COVID-19 Pandemic
}

\author{
Hemendra Singh ${ }^{1 *}$ and Swati $\mathrm{C}^{2}$ \\ ${ }^{1}$ Assistant Professor, Department of Psychiatry, MS Ramaiah Medical College, India \\ ${ }_{2}^{2} J u n i o r$ Resident, Department of Psychiatry, MS Ramaiah Medical College, India
}

Submission: February 12, 2022; Published: February 24, 2022

*Corresponding author: Dr. Hemendra Singh, Assistant Professor, Department of Psychiatry, MS Ramaiah Medical College India

Keywords: COVID-19; Suicide; Mental health; Psychopathology; Gatekeepers

Abbreviations: WHO: World Health Organization; CNS: Central Nervous System; ACE-2 : Angiotensin-Converting Enzyme 2; CRH: Corticotropin Releasing Hormone; mTOR: Mammalian Target of Rapamycin

\section{Introduction}

Suicide is defined as death caused by injuring or harming oneself with intent to die and a suicide attempt is an injury or harm caused to self with intent to die but has not resulted in death [1]. Suicide and suicidal behaviors are influenced by multiple psychosocial and biological factors. Factors such as resilience, good social support are protective against suicide while lack of occupation, financial issues, ill health, poor social support are risk factors of suicide. Prevention of suicide is the need of the hour. Amidst the COVID-19 pandemic is a possible suicide and suicidal behavior increase that is being neglected at community level.

\section{Burden of Suicide}

World Health Organization (WHO) statistics show that globally more than 800,000 people die by suicide every year, that is, one death by suicide occurs every 40 seconds. For every completed suicide there are 10-20 suicidal attempts that are reported [2]. About $77 \%$ of all suicides occur in low and middle income countries [3]. In India, as per National Crime Records Bureau of India 1.53 lakh people have died by suicide in the year 2020 (vs 1.39 lakh in 2019). The most common form of suicide being death by hanging followed by death by consumption of poisons especially insecticides. Total rate of suicides nationwide is $11.3[4,5]$. Though global statistics collected by WHO shows that the rate of suicides have reduced between 2010 and 2019 in lowmiddle income countries, statistics from India does not reflect this [6].
Influence of COVID -19 pandemic on suicide and suicidal behavior

Suicide and self-harm behavior are influenced by multiple psychological, social and illness aspects and reflects the severity of the mental health crisis and illness in a given community. COVID-19 infection has impacted the psychological, social and physical health globally and thus self-harm and suicide behavior as well. A study in Nepal has shown that suicide rates were higher during lockdown than immediate post lockdown period and same time period of pre-COVID years. Delay in arrival to hospital, admissions and in hospital deaths due to self-harm were also higher during lockdown [7]. Indian study compiled from news reports and social media showed that more than half of them were tested positive for COVID-19, about one-third was in institute setting and that the most common mode of suicide was by hanging followed by fall from height.

Nearly two-thirds of the patients had contacted a physician within 2 weeks prior to their self-harm. More than $80 \%$ of the people who completed suicide did not have pre-existing psychiatric or physical co-morbidities [8]. This may indicate that COVID-19 pandemic and its effect on psychological health and social factors may be an independent risk factors for suicide. Comparing preCOVID data with the current data shows that depressive illness has increased two to three fold than before. Anxiety and stress levels in the general population have also increased significantly 


\section{Global Journal of Addiction \& Rehabilitation Medicine}

[9-11]. As $90 \%$ of people who have completed suicide have a preexisting psychiatric diagnosis [12], increase in psychiatric illness can lead to increase in suicidal behavior.

\section{Psychosocial factors influencing suicidal behavior during COVID-19 pandemic}

Studies have shown that stressors related to COVID-19 infections such as fear of infection, increased vigilance about changes in body and wrongly attributing it to COVID-19 infection, deterioration of physical health due to COVID-19 infection, reduced social support and caregiver ability have impacted the mental health of the people [13]. People who follow COVID-19 related news closely are more prone to develop anxiety as most of the news is distressing and emphasizes the infectivity of the virus and its associated morbidity and mortality. Rumors, fabrications and misinformation on social media also contribute to the rising anxiety levels and exacerbate depressive symptoms [14-16]. Isolation due to lockdowns, work from home and infection can cause loneliness, helplessness and stress. Physical isolation with social and emotional closeness by using social networks and virtual platforms can be a protective factor [17].

\section{Pathogenesis of psychopathology associated with COVID-19 infection}

COVID-19 or SARS CoV 22019 is well known for its entry through mucosal surfaces and its effect on respiratory system, morbidity and mortality associated with the same. However, lesser-known fact is that SARS Cov-2 infection and associated immune response affects multiple organs and organ systems of the body; one such system being the Central Nervous System (CNS). SARS CoV-2 virus enters the epithelial cells via angiotensinconverting enzyme 2 (ACE-2) receptors. This in turn leads to down-regulation of ACE- 2 receptors expression. In animal studies down-regulation of ACE-2 expression has resulted in increased sympathetic activity, reduced tryptophan uptake and production of serotonin; thus, compromising the body's ability to respond to stress and hence increasing the individual's susceptibility to depression and anxiety.

ACE-2 receptors in hypothalamus suppress fear responses, anxiety and its related behavior as well as Corticotropin releasing hormone (CRH) which plays an important role in response to physiological stress. ACE-2 receptor down-regulation hampers negative feedback mechanism of glucocorticoids in reducing excessive inflammation. Therefore, in SARS CoV 2 infection an excessive and dynamic inflammation is observed. SARS CoV 2 virus has the ability of infecting all tissue having the ACE- 2 receptor including the brain tissue. Hence, direct infection and increased immune response both play a role in pathogenesis of psychiatric illnesses associated with COVID-19 illness. This can be prevented by preformed antibodies occupying the ACE2 receptors in the brain thus preventing entry of the virus into the neuronal cells. Hence, ACE-2 receptor modulator drugs may have a role in treatment of COVID-19 infection and prevention of psychiatric complications [13].

Though rennin angiotensin aldosterone system plays a role in pathogenesis of stress related depression and anxiety, it is minimal. Bradykinin and mammalian target of rapamycin (mTOR) play a major role in depression and effect of COVID-19 infection on them is not known [13]. Inflammatory mechanisms activated by SARS CoV 2 virus increase inflammatory cytokines such as TNF-A, Interleukin 6 and Interferons in both peripheral and central tissues leading to cell apoptosis. This leads to increased risk of developing mood disorders, anxiety and psychosis. Hence, augmenting antidepressant or anti-psychotic drugs with immunomodulatory drugs or anti-inflammatory drugs are more beneficial than antidepressant or anti-psychotic drug treatment alone [13]. Effect of COVID-19 pandemic on pre-existing psychiatric illness and access to mental health care services.

The COVID-19 pandemic, precautionary measures implemented to limit its spread and burden on the health care services due to infection had a major impact on non-pandemic related illnesses and treatment for the same. Restrictions in movement, transport, burden on health care infrastructure made accessing health care services in timely manner difficult globally $[18,19]$. This has also had an effect on the help seeking attitude and availability of services for people with pre-existing mental illnesses. Re-allocation of all available services in health care services including mental health care professionals to tackle the burden of COVID pandemic may have resulted in lack of timely professional help for people with mental illnesses [20]. As psychiatric facilities were found to be a high risk area of spread of COVID-19 infection, community based or home based treatment through telepsychiatry, psychological support and home delivery of the medications would have been recommended and ideal.

However, due to sudden and unexpected impact of the pandemic mental health services were not equipped to handle this crisis [20]. Study comparing people with pre-existing psychiatric illnesses and those without showed that people with psychiatric illnesses had significantly higher depression, anxiety, stress, PTSD like symptoms, anger, impulsivity and suicidal ideation [21]. Lack of access to mental health care services and medications could have resulted in untreated mental illnesses and above findings. This results in impaired ability of the individuals to cope with stress and in turn cause increase in suicidal ideation and attempts.

\section{Bridging the gap...Gatekeeper?}

In India, there exists a huge gap between the requirement of mental health services and the personnel who are trained to provide adequate services. The National Mental Health Survey of 2015-2016 shows that lifetime risk of psychiatric illness is $13.67 \%$ and point prevalence was $11.56 \%$. But the available mental health professionals were 0.3 per 100,000 population for psychiatrists, 
0.07 per 100,000 population for clinical psychologists and 0.12 for mental health nursing staff [22]. To meet the minimum mental health needs of the population of India there should be 3 psychiatrists per 100,000 populations and for optimum care or in an ideal situation 6 psychiatrists per 100,000 populations. Keeping attrition rate of psychiatrists to $0 \%$, approximately 2700 new psychiatrists need to be trained annually the next 10 years to meet the demands of our country [23].

However, as of 2021-2022 academic year approximately 1200 Post-graduate students are being trained as psychiatrists throughout the country, which is less than half the required numbers [24]. COVID pandemic has also increased the risk factors for suicide thus increasing the need for mental health services in prevention of suicide. Gatekeepers can help in bridging this gap. Gatekeeper refers to people who have primary contact with individuals at risk for suicide, and who can identify such individuals by recognizing suicidal risk factors and refer to a professional. Gatekeeper training refers to training individuals to identify risk factors for suicide among people and refer for appropriate help [25]. Gatekeeper could be teachers, family members, supervisors, religious leaders, faith healers, physicians, police, colleagues and friends. Most of them are however not aware of the signs that people who have risk of suicide exhibit and hence are unable to identify and provide timely health.

Most of the people in the community, especially the youth are hesitant approaching mental health professionals for help for suicide due to stigma attached with suicide and lack of awareness of avenues of help available and fear of being judged. Often times when they approach lay people for help with suicidal ideation, their concerns are trivialized or ignored (probably due to ignorance and their own discomfort regarding suicide) making them hesitant to reach out for help again. Gatekeeper training is a strategy designed to improve early identification of individuals at high risk for suicide and to facilitate timely mental health referrals, responding to the fact that suicidal youth are under-identified and few are using these services.

Identifying people who have contact with population at large and adequate training to recognize and provide first aid for people with risk of suicide before professional help is available becomes important. Educational institutes (like schools, colleges and universities) and workplaces should have a crisis management team who have had gatekeeper training from professionals. Crisis team should include people from the administration and employees who are willing to undergo gatekeeper training and help in suicide prevention.

\section{References}

1. (2021) Facts About Suicide. CDC.

2. (2022) Mental health. WHO fact sheet.

3. (2022) Suicide. Newsroom. WHO fact sheet.

4. (2020) Accidental death and suicide data. NCRB.
5. (2022) Accidental death and suicide data. NCRB.

6. (2021) World Health Statistics 2021: A visual summary.

7. Shrestha R, Siwakoti S, Singh S, Shrestha AP (2021) Impact of the COVID-19 pandemic on suicide and self-harm among patients presenting to the emergency department of a teaching hospital in Nepal. PLoS One 16(4): e0250706.

8. Panigrahi M, Pattnaik JI, Padhy SK, Menon V, Patra S, et al. (2021) COVID-19 and suicides in India: A pilot study of reports in the media and scientific literature. Asian J Psychiatr 57: 102560.

9. Catherine KE, Salma MA, Gregory HC, Laura S, Patrick MV, et al. (2020) Prevalence of Depression Symptoms in US Adults Before and During the COVID-19 Pandemic. JAMA Network Open 3(9): e2019686.

10. Huang Y, Zhao N (2020) Generalized anxiety disorder, depressive symptoms and sleep quality during COVID-19 outbreak in China: a web-based cross-sectional survey. Psychiatry Res 288: 112954.

11. Hyland P, Shevlin M, McBride O, Murphy J, Karatzias T, et al. (2020) Anxiety and depression in the Republic of Ireland during the COVID-19 pandemic. Acta Psychiatr Scand 142(3): 249-256.

12. Arsenault-Lapierre G, Kim C, Turecki G (2004) Psychiatric diagnoses in 3275 suicides: a meta-analysis. BMC Psychiatry 4: 37.

13. Esme Jansen van V, Stephan FS, Christiaan BB, Marisa Moller, Francois PV, et al. (2021) The neuropsychiatric manifestations of COVID-19: Interactions with psychiatric illness and pharmacological treatment. Biomed Pharmacother 135: 111200.

14. Shuang-Jiang Z, Li-Gang Z, Lei-Lei W, Zhao-Chang G, Jing-Qi W, et al. (2020) Prevalence and socio-demographic correlates of psychological health problems in Chinese adolescents during the outbreak of COVID-19. Eur Child Adolesc Psychiatry 29(6): 749-758.

15. Moghanibashi-Mansourieh A (2020) Assessing the anxiety level of Iranian general population during COVID-19 outbreak. Asian J Psychiatr 51: 102076

16. (2020) Mental health and psychosocial considerations during the COVID-19 outbreak, 18 March 2020. World Health Organization.

17. Banerjee D (2020) The COVID-19 outbreak: Crucial role the psychiatrists can play. Asian J Psychiatr 50: 102014.

18. Gautam R, Sharma M (2020) 2019-nCoV pandemic: A disruptive and stressful atmosphere for Indian academic fraternity. Brain Behav Immun 88: 948-949.

19. Joob B, Wiwanitkit V (2020) Traumatization in medical staff helping with COVID-19 control. Brain Behav Immun 87: 10.

20. Kim S-W, Su K-P (2020) Using psychoneuroimmunity against COVID-19. Brain Behav Immun 87: 4-5.

21. Fengyi H, Wanqiu T, Li J, Ling Z, Xinling Z, et al. (2020) Do psychiatric patients experience more psychiatric symptoms during COVID-19 pandemic and lockdown? A case-control study with service and research implications for immunopsychiatry. Brain Behav Immun 87: 100-106.

22. (2015) World Health Statistics 2015. World Health Organization.

23. Garg K, Kumar CN, Chandra PS (2019) Number of psychiatrists in India: Baby steps forward, but a long way to go. Indian J Psychiatry 61(1): 104-105.

24. College and Course Search. NMC.

25. Isaac M, Elias B, Katz LY, Belik S-L, Deane FP, et al. (2009) Gatekeeper Training as a Preventative Intervention for Suicide: A Systematic Review. Can J Psychiatry 54(4): 260-268. 
This work is licensed under Creative Commons Attribution 4.0 License DOI: 10.19080/GJARM.2022.06.555698
Your next submission with Juniper Publishers will reach you the below assets

- Quality Editorial service

- Swift Peer Review

- Reprints availability

- E-prints Service

- Manuscript Podcast for convenient understanding

- Global attainment for your research

- Manuscript accessibility in different formats ( Pdf, E-pub, Full Text, Audio)

- Unceasing customer service

Track the below URL for one-step submission https://juniperpublishers.com/online-submission.php 